\title{
Retrospective Study of Suicide Among Children and Young Adults
}

\author{
Mishra N¹, Shrestha D², Poudyal RB ${ }^{3}$, Mishra $\mathrm{P}^{4}$ \\ ${ }^{1}$ Dr. Navin Mishra, MBBS, MD (Paediatrics) Assistant \\ Professor, Department of Paediatrics, KIST Medical \\ College, Imadol, Lalitpur, Nepal, ${ }^{2}$ Dr. Devendra \\ Shrestha, MBBS, MD (Paediatrics) Assistant \\ Professor, Department of Paediatrics, KIST Medical \\ College, Imadol, Lalitpur, Nepal, ${ }^{3}$ Dr. Rakesh Babu \\ Poudyal, MBBS, MD (Paediatrics) Assistant Professor, \\ Department of Paediatrics, KIST Medical College, \\ Imadol, Lalitpur, Nepal, ${ }^{4} \mathrm{Dr}$ Pravin Mishra, MBBS, \\ Resident (Family Medicine), National Academy of \\ Medical Sciences, Kathmandu, Nepal.
}

\section{Introduction}

Quicide is defined as a potentially self-injurious behavior associated with expressed or implied intent to die ${ }^{1}$. It is a worldwide problem and has shown an upward surge across the world. Suicide is among the top 20 leading causes of death globally in all ages ${ }^{2}$. An even more disturbing fact is that suicide was rated as the fourth leading cause of death among children between the ages of 10 and 14 years $^{3}$. The latest mean worldwide annual rates of suicide per 100000 were 0.5 for females and 0.9 for males among 5-14 year olds, and 12.0 for females and 14.2 for males among 15-24 year olds, respectively 4 . A Norwegian study showed the annual suicide rate for $15-19$ years was 18.6 per 100,000 per year for boys and 6.3 for girls, and for ages 10-14 years was 2.7 for boys and 0.5 for girls in 1990-1992 AD .

Recently, the Maternal Mortality and Morbidity Study 2008/2009 undertaken by the Department of Health Services in Nepal identified that suicide is the leading cause of death among women of reproductive age (15-49 years), accounting for almost 16 percent of deaths in that age group 6 . To the best of our knowledge there is no published data on suicide among Nepalese children and young adults. Hence, we carried out this study to determine the prevalence and cause of suicide as well as to identify the specific vulnerable groups of children and young adults to suicide.

\section{Address for correspondence \\ Dr. Navin Mishra \\ Tripti Marg-57, Shanti Nagar, \\ New Baneshwor, Kathmandu \\ Nepal \\ E-mail: drnavin4@yahoo.com}

\begin{abstract}
Introduction: The prevalence of suicide has been increasing globally in all age groups. There is dearth of literature on suicide among younger patients from developing country. The objective of this study was to find out the prevalence and cause of suicide as well as to identify the vulnerable groups of children and young adults to suicide. Materials and Methods: This is a retrospective observational study. Data was collected from the Police Head Quarters in Kathmandu and included all completed suicide cases of less than twenty one years of age from January 2005 to December 2009. Results: There were a total of 2172 documented cases of completed suicide in the age group between 4 to 21 years. The majority were female and belonged to the adolescent age group. The incidence of suicide showed an increasing trend within the five years of the study. A monthly breakdown of the cases revealed that the incidence of suicide was lowest in January and February and peaked from April to October. Hanging was the most common mode of suicide followed by poisoning and drowning. The reason for suicide could be ascertained only among 25.5 $\%$ of cases. Domestic violence (35\%), mental illness $(24 \%)$, failure in academic achievement $(15.8 \%)$ and end of a romantic relationship $(8.7 \%)$ were found to be common causes of committing suicide. Of the 87 cases found who committed suicide because of academic failure $46.6 \%$ were at a grade ten level. Conclusions: Suicide in children and young adults in Nepal appears to be a concealed but serious problem requiring immediate attention and systematic efforts.
\end{abstract}

Key words: Suicide, Children, Nepal, Mortality, School

\section{Materials and Methods}

This was a retrospective study which studied all completed suicide of children and young adults under the age of 21 years reported to Nepal Police Headquarter.

\footnotetext{
How to cite this article?

Mishra N, Shrestha D, Poudyal RB, Mishra P. Retrospective Study of Suicide Among Children and Young Adults. J Nepal Paediatr Soc 2013;33(2):110-116.
} 
from January 2005 to December 2009. The data was collected from the registers and case files maintained in the Nepal Police Headquarter.

In general, the Police Headquarter receives the reports of criminal cases from all the districts of Nepal. Every case of unnatural death in Nepal is investigated by the Police Officer and forwarded to court for the trial to differentiate between homicide and suicide based on the information collected from eye witnesses, family members, suicide notes, medical and autopsy reports. Suicides among those more than twenty one years of age, failed suicidal attempts and cases with inconclusive police investigations were excluded from the study.

Demographic data, ethnicity, religion, mode of suicide, level of education, date of suicide and suspected reasons of suicide (where available) were collected during the data collection process. The population of different age groups in Nepal was obtained from the Central Bureau of Statistics, Kathmandu. The age groups were then classified into preschool (3 to 6 years), school age ( 7 to 12 years) and adolescent (13 to 21 years). The data were analyzed using SPSS version 13.0 statistical software.

\section{Results}

There were a total of 2172 cases of completed suicide recorded among the selected age groups during the five year period. Data revealed that the age spread for suicide ranged between 4 and 21 years with $92.4 \%$ belonging to the adolescent age group. There were 9 cases in the preschool age group, 157 cases in the school age group and 2006 cases in the adolescent age group [Table 1]. Overall, $72.4 \%$ were female. The ratio of males to females in non-adolescents (preschool and school age group) was similar but suicides in female adolescents were alarmingly high compared to non adolescents (Chi square $=45.01, \mathrm{df}=1, \mathrm{p}<0.001$ ).

We found that the annual incidence of suicide (Table 2) among adolescents increased dramatically over the study period from 5.8 in 2005 to 15.7 in 2009 per 100,000 populations in that age group.

With regard to ethnicity, suicide cases were found in all major ethnic groups of Nepal and were more common among Brahmins (18.4\%), Chhetris (15.6\%), Rais $(6 \%)$, Tharus $(10 \%)$ and Magars $(4.1 \%)$. The Chaudharys were most commonly associated with a higher incidence of suicide, constituting $7.7 \%$ of total cases. Religion wise, most suicides were among Hindus $(89.7 \%)$, followed by Buddhists $(6.6 \%)$ and Muslims $(2.4 \%)$.

The incidence of suicide in the study was found to be increasing rapidly (Figure 1) in the five year period. The year-round analysis (Figure 2) revealed that the incidence of suicide was lowest in January and February, and peaked in April and October. It can be noted that among the 87 deaths due to academic failure, 34 deaths (39\%) had occurred in June-July, the period when results of most academic sessions are published.

A geographic analysis of these cases revealed an equal distribution throughout the country. Jhapa district showed the highest incidence of suicide 167 (7.7\%), followed by Morang 111 (5.1\%). The Eastern development region $(785,36.1 \%)$ was found to be the most affected, followed by the Central Development Region (22.5\%). According to zonal distribution, the Koshi zone comprised the highest number, 272 (12.5\%) of cases, followed by Sagarmatha (12\%) and Mechi (11.7\%).

Analysis revealed hanging (Table 3 ) as the most common mode $(58.8 \%)$ of suicide followed by poisoning (36\%), drowning (2.9\%), burning (1.1\%), jumping from height $(0.5 \%)$ and others $(0.7 \%)$. Further analysis revealed that adolescents were less likely to choose hanging than non-adolescents; however, the odds ratio was insignificant $[\mathrm{OR}=0.865,95 \% \mathrm{Cl}=$ $0.624,1.198]$. Hanging was found to be more preferred among the school age group with a ratio of population committed suicide with hanging as compared to other modes were 1.85:1 while that of in the pre-school age and adolescents were $1: 8$ and $1.4: 1$ respectively. Self burning was more common in females than in males, with a ratio of 4.75: 1 . Similarly, the ratio of females to males committing suicide by poisoning was $2.98: 1$, whereas the female:male ratio of those committing suicide by hanging, drowning and jumping were 2.6:1, $1: 1$ and $2: 3$ respectively.

The reasons for suicide were known in 551 cases (Table 4). The majority of suicide cases were attributed to domestic violence (35\%), followed by mental disorders $(23.9 \%)$, failure in academic achievement $(15.8 \%)$, and the end of romantic relationships (8.7\%). Among the cases of domestic violence, deaths due to parental abuse were $13.5 \%$ and due to teachers' abuse were $2 \%$. Among the 87 deaths due to academic failure, 40 cases $(46.6 \%)$ belonged to grade ten (Figure 3 ). Deaths due to academic failure were significantly high in the adolescent age group (95.4\%) as compared to the school age group (4.6\%). Suicide due to the end of romantic relationships was five times higher in females than in males. Besides these, other reasons of suicide included marital discord, physical illness, poverty and imitating television drama. Among the cases reported to be due to marital discord, all but one were female. We also found that among suicide in the preschool age 
group, reasons were known in only two cases, and both were related to domestic violence which included scolding by parents and family. The literacy status was known only in 640 cases. Interestingly, $94.7 \%$ of this study population was literate. Furthermore, information about actual educational level was known only in 440 cases (Figure 3) among which 129 (27.2\%) were in grade ten level.

Table 1: Age and sex distribution $(n=2172)$

\begin{tabular}{|l|c|c|c|}
\hline Age & Male & Female & Total(\%) \\
\hline Preschool age (3 to 6 years) & 3 & 6 & $9(0.4 \%)$ \\
\hline School age ( 7 to 12 years) & 80 & 77 & $157(7.2 \%)$ \\
\hline Adolescents (13 to 21 years) & 517 & 1489 & $2006(92.4 \%)$ \\
\hline
\end{tabular}

Table 2: Incidence of suicide in different age group from 2005 AD to 2009 AD

\begin{tabular}{|l|c|c|c|c|c|}
\hline & $\begin{array}{c}\text { 2005 AD N (case } \\
\text { per 100,000) }\end{array}$ & $\begin{array}{c}\text { 2006 AD N (case } \\
\text { per 100,000) }\end{array}$ & $\begin{array}{c}\text { 2007 AD N (case } \\
\text { per 100,000) }\end{array}$ & $\begin{array}{c}\text { 2008 AD N (case } \\
\text { per 100,000) }\end{array}$ & $\begin{array}{c}\text { 2009 AD N (case } \\
\text { per 100,000) }\end{array}$ \\
\hline Preschool age group & $0(0)$ & $0(0)$ & $1(0.04)$ & $4(0.15)$ & $4(0.15)$ \\
\hline School age group & $16(0.42)$ & $18(0.48)$ & $26(0.7)$ & $43(1.14)$ & $54(1.43)$ \\
\hline Adolescents & $203(5.08)$ & $192(4.8)$ & $495(12.38)$ & $489(12.2)$ & $627(15.7)$ \\
\hline Birth to 21 years & $219(1.2)$ & $210(1.1)$ & $522(2.86)$ & $536(2.9)$ & $685(3.75)$ \\
\hline
\end{tabular}

Table 3: Mode of suicide in different age group $(n=2172)$

\begin{tabular}{|l|c|c|c|c|c|c|}
\hline & Hanging & Poisoning & Drowning & $\begin{array}{c}\text { Fall from } \\
\text { height }\end{array}$ & Burn & Others $^{* *}$ \\
\hline Preschool & 1 & 6 & 1 & 0 & 1 & 0 \\
\hline School & 102 & 38 & 9 & 1 & 4 & 3 \\
\hline Adolescence & 1175 & 738 & 54 & 9 & 18 & 12 \\
\hline
\end{tabular}

**Others: includes 3 cases of electric shock and mode of 12 cases of suicide were not documented

Table 4: Suspected cause of suicide in less than 21 years old $(n=551)$

\begin{tabular}{|c|c|c|c|c|c|c|c|c|c|}
\hline & $\begin{array}{c}\text { Domestic } \\
\text { violence }\end{array}$ & $\begin{array}{c}\text { Academic } \\
\text { failure }\end{array}$ & $\begin{array}{c}\text { Love } \\
\text { affair }\end{array}$ & $\begin{array}{c}\text { Marital } \\
\text { discord }\end{array}$ & $\begin{array}{c}\text { Mental } \\
\text { disorders }\end{array}$ & $\begin{array}{c}\text { Physical } \\
\text { illness }\end{array}$ & $\begin{array}{c}\text { Copying } \\
\text { television } \\
\text { show }\end{array}$ & Poverty & Others** \\
\hline Preschool & 2 & 0 & 0 & 0 & 0 & 0 & 0 & 0 & 0 \\
\hline School & 18 & 4 & 0 & 0 & 4 & 0 & 3 & 2 & 1 \\
\hline Adolescent & 173 & 83 & 48 & 14 & 128 & 12 & 2 & 48 & 9 \\
\hline Total & $\mathbf{1 9 3}$ & $\mathbf{8 7}$ & $\mathbf{4 8}$ & $\mathbf{1 4}$ & $\mathbf{1 3 2}$ & $\mathbf{1 2}$ & $\mathbf{5}$ & $\mathbf{5 0}$ & $\mathbf{1 0}$ \\
\hline
\end{tabular}

** Others include: 3 cases due to deep sorrow because of demise of husband, sister and parents respectively, 2 cases because of unable to conceive, 3 cases due to guilt and impulsiveness, 1 cases because favorite soccer team lost world cup, 1 case because of being unable to attend dance party

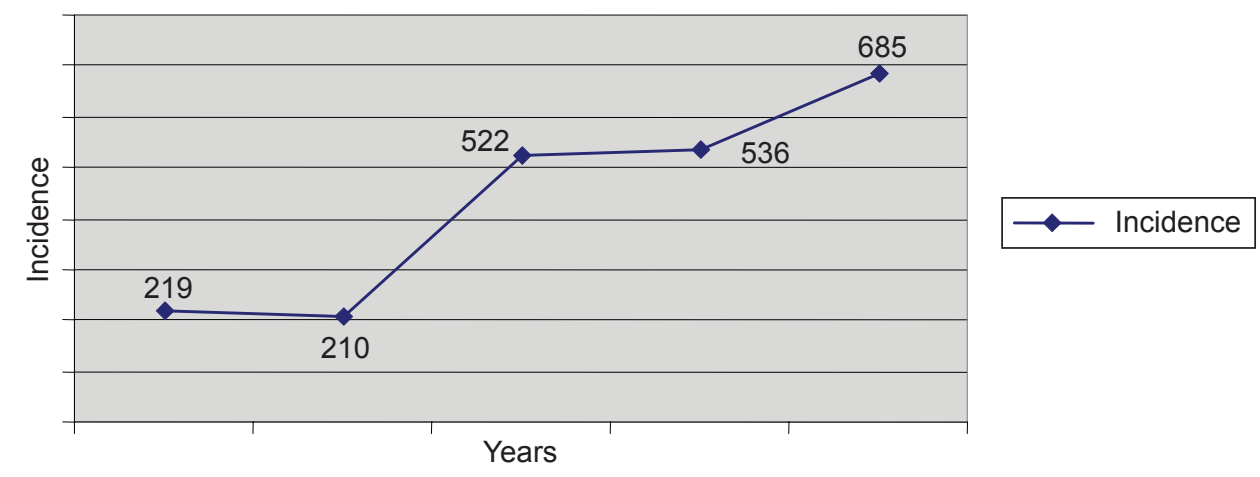

Fig 1: Yearly incidence of completed suicide in less than 21 years 


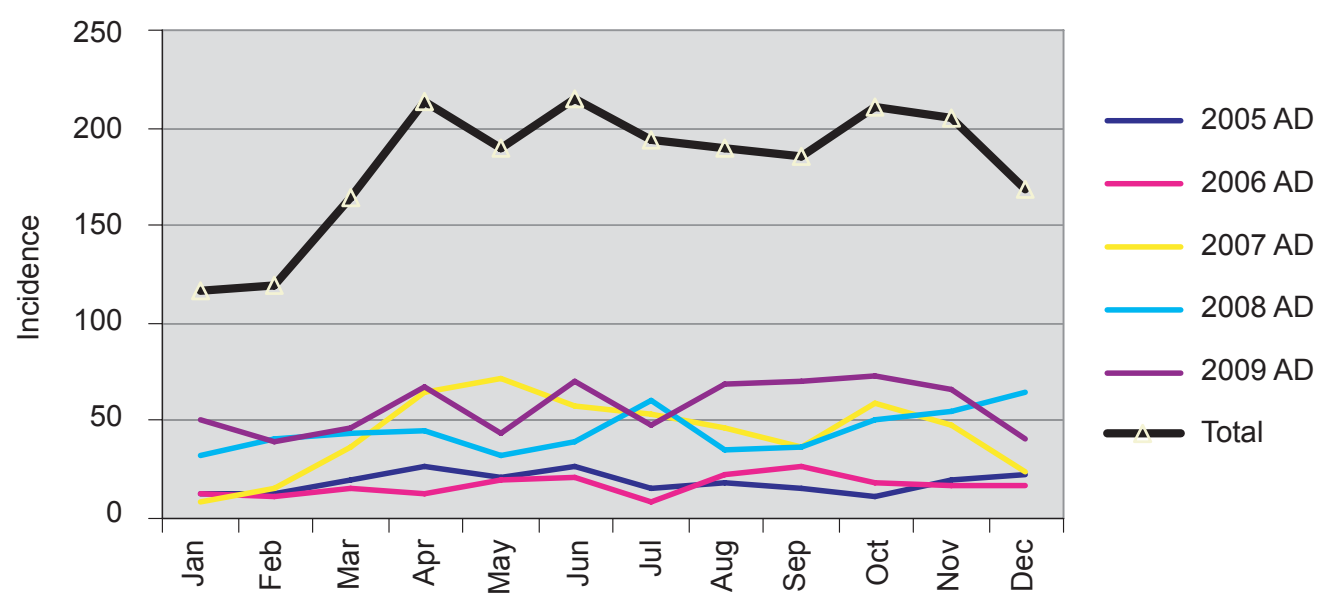

Fig 2: Incidence of suicide in less than twenty one years old in different months

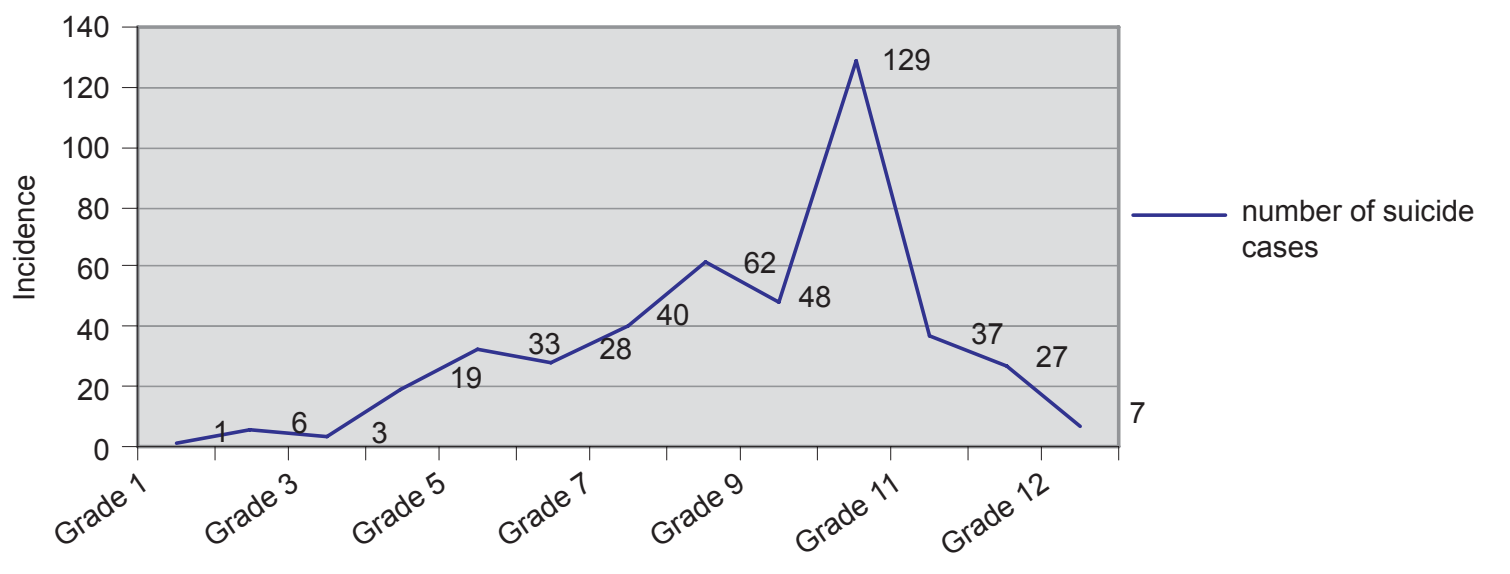

Fig 3: Incidence of suicide in different grades of students from 2005 AD to 2009 AD ( $n=440$ )

\section{Discussion}

Age is an important biological factor associated with suicidal ideation. Studies have shown that although the prevalence of completed suicide among children is lower as compared to other age groups, suicidal thoughts and behaviors in children are quite common ${ }^{7,8}$. In this study, we found that the incidence of suicide rose with increasing age, and was more common in adolescents. The actual problem of suicide in these populations may be still higher than these figures if attempted suicide were to be considered. As per the data from the United States there may be 8-25 attempted suicides for every completed suicide ${ }^{9}$.

Our study revealed that the incidence of completed suicide is higher among females than males. However, this gender difference in incidence was only observed starting at 12 years of age. This is in accordance with a study from the western region of Nepal, where suicide attempts were found to be more common in young females, and reaction to stress was the most common risk factor ${ }^{10}$. The high suicide rate in adolescent females may be explained by the gender discrimination adopted in Nepalese society. In India too, the majority of suicides in children and adolescents were found among girls (F:M 1.24:1) ${ }^{11}$. Interestingly, in most other countries, males outnumber females in youth suicide statistics. For example, in Hong Kong, male adolescent (10-24 year) suicide rates were in general higher than in females ${ }^{12}$. Similarly, in Canada, the M:F ratio was $2.4: 1$ and in Turkey, males $(60 \%)$ predominated ${ }^{13,14}$.

Our study showed no significant difference in the incidence of suicide based on ethnicity, religion or geographical distribution. The incidence among different ethnicities and religions corresponds to the population distribution of different ethnicities in Nepal. However, literate population was predominant over illiterate in the study group who committed suicide. We hypothesize that the reason for this difference may be that the illiterate people have little access to the competitive world, making them less exposed to mental frustration and challenges. 
Hanging was found to be the most common mode for suicide followed by poisoning, drowning, burning and jumping from a height. This finding was similar to the findings reported in a previous study carried out in the eastern region of Nepal, which had found hanging the most common mode of suicide ${ }^{15}$. Also, similar results were found in Indian, Austrian and Turkish studies ${ }^{11,14,16}$. However, in Hong Kong, jumping from height was the most common method for committing suicide in adolescents ${ }^{12}$. In the United States, gunshot was the most common method overall $(58 \%)$, followed by hanging $(30 \%)^{17}$. The use of certain methods for committing suicide largely depends on availability, accessibility and socio-acceptability of opportunities to commit suicide in the everyday environment.

Seasonal variation in suicide prevalence is one of the oldest and most resistant-to-elucidation issues in suicide research. In general, suicidal tendency peaked in spring and early summer and declined in the winter months. Similar to the present study, the suicides during 1969-1994 in Switzerland also peaked in May and June and declined in December ${ }^{18}$. The high suicide period in Nepal could be partially attributed to the end of academic session of school when the final results in schools are published.

There appears to be a number of differences in the etiology, presentation and treatment options for mental health problems between high-resource and low-resource countries ${ }^{19}$. In our study we found various reasons of suicide in this age group. Domestic violence, which encompasses violence from parents, family members and teachers and physical or psychological abuse, was found to be the most dominant reason given for suicide. This shows that poor parenting of the child was directly related to these cases. This was also evidenced in a study by Beautral et al where significant association of suicidal behavior was observed with poor parental relationship, communication and childhood institutional care ${ }^{20}$.

In our study, suicide due to failure in academics is significantlyhigh in the adolescentage group as compared to school age group. There were 87 cases suspected to have committed suicide because of academic failure among which $46.6 \%$ belonged to a grade ten level. Passing School Leaving Certificate Examination (board exam after class ten) has considerable social pressure and soaring ambition in students at this level is considered to be the Iron Gate by many students. These collective strains on the students may be the cause of high incidence of suicide in students of this age group. The association between school or academic stressors and suicide ideation among adolescents has been well documented in several research studies ${ }^{21,22}$. Also, Ang et al found academic stress on students had a significant correlation with both depression and suicidal ideation ${ }^{23}$.

Socioeconomic status has been associated with suicide in various studies. In the present study, poverty was the reason for suicide in $9 \%$ of cases. A study done by Gould et al demonstrated a relationship of suicide with lower socioeconomic status and unemployment among 120 suicide victims less than 20 years of age ${ }^{24}$. In contrast, a Finnish study among 110 adolescents who committed suicide found no difference in socioeconomic status $^{25}$.

Similarly, the end of a romantic relationship has also been a common reason for suicide in teenagers. $8.7 \%$ of cases in our study were related to a problem in a romantic relationship and all occurring to adolescents. Also, a study from New Zealand discovered a strong association of suicidal tendency in young adults due to the end of a romantic relationship ${ }^{26}$.

Television exposure to suicide has also been considered as a risk factor for suicide. In a study done by Schmidtke et al in the United States, it was noted that the suicide rate increased by $175 \%$ before and after exposing young adults to televised suicide ${ }^{27}$. On the contrary, a study by Simkin et al found no evidence of effect of TV exposure to suicide ${ }^{28}$. In our study, only $0.9 \%$ was related directly to exposure to TV shows with suicide. This relationship may increase as there is an increasing availability of satellite channels in Nepal.

In our study, $24 \%$ of the suicidal cases had a previous diagnosis of a mental disorder however the exact disorder was not established. Grøholt et al. found that $74 \%$ of children and adolescents who completed suicide had a mental disorder and the main risk factors identified were depression, disruptive disorders and previous suicidal behavior ${ }^{5}$.

The results should be viewed on the background of certain limitations of our study. The primary limitation of our study is that this being a retrospective study based mainly on police records lacked the uniformity of every detail about the cases. Besides that, it would be inconclusive to draw an inference on causes of suicide as it lacked details of coexisting psychiatric illness prior suicide. Also, the chance of under reporting as well as over reporting of these cases cannot be completely ruled out. As per a Norwegian study on suicide in young children under 15 years of age, uncertain or improbable suicides were significantly more common in the very young and hence some accidents might wrongly be classified as suicide ${ }^{29}$. In contrary, there is also the possibility of the police not being notified of some cases especially from remote places in Nepal. 
Not only that there is still a high chance of missing case files from records especially those during the years of conflict in Nepal when several police offices were destroyed. Besides that, the social structures, norms and stigma forbid from reporting suicide to the police as the community tries to settle the problem on their own without notifying. Despite these shortcomings, this study throws light on the concealed problem of suicide among young population and points toward some implications for intervention and control of the suicide.

\section{Conclusion}

This study identifies the suicide as significant concealed problem in Nepalese children and young adults. Though adolescent female remains the most vulnerable population, the etiology and nature of suicide significantly differs in different groups. Multisectoral approach involving school based age and gender specific intervention, healthy education system, better domestic environments and timely treatment of mental illness may play a key role in preventing suicides.

Acknowledgements: We are grateful to all the staffs of Police Headquarter of Kathmandu for permitting access to the data and supporting our during data acquisition. We are also thankful to Dr Bibha Dhungel for helping us with data collection.

Conflict of Interest: None reported

Funding: Nil

Permission from IRB: Yes

\section{References}

1. Posner K, Oquendo MA, Gould M, Stanley B, Davies M. Columbia Classification algorithm of Suicide assessment (C-CASA): classification of suicidal events in the FDA's pediatric suicidal risk analysis of antidepressants. Am J Psyc 2007;164:1035-43.

2. WHO. Suicide Prevention. [Online]. 2010 Jul 30 [cited 2010 Sep 11]; Available from: URL: http:// www.who.int/mental_health/prevention/en/

3. Friday JC. The psychological impact of violence in underserved communities. J Health Care Poor Underserved. 1995;6(4):403-9.

4. Pelkonen M, Marttunen M. Child and adolescent suicide: epidemiology, risk factors, and approaches to prevention. Paediatr Drugs 2003;5(4):243-65.

5. Grøholt B, Ekeberg O, Wichstrøm L, Haldorsen T. Youth suicide in Norway, 1990-1992: a comparison between children and adolescents completing suicide and age- and gender- matched controls. Suicide Life Threat Behav 1997;27(3):250-63.

6. Maternal Mortality and Morbidity Study 2008/2009 undertaken by the Family Health Division (FHD) of the Department of Health Services. Available from: URL :http://www.upiasia.com/Society_ Culture/2010/01/25/nepal_dying_to_escape/9773/

7. Davidson LE, Rosenberg ML, Mercy JA, Franklin J, Simmons JT. An epidemiologic study of risk factors in two teenage suicide clusters. JAMA 1989;262:2687-92.

8. Velez C, Cohen P. Suicidal behavior and ideation in a community sample of children: maternal and youth reports. J Am Acad Child Adolesc Psychiatr 1988;27:349-56.

9. American Foundation For Suicide Prevention. National Statistics [Online]. 2010 [cited 2010 Oct 12]; Available from: URL: http://www.afsp.org/ index.cfm?fuseaction=home.viewpage\&page_ $i d=050 f e a 9 f-b 064-4092-b 1135 c 3 a 70 d e 1 f d a$

10. Halder S, Thapa P, Khatri JB, Ramesh K, Chakravarti PK. Sociodemographic and clinical characteristics of cases with suicidal attempts: A hospital based study. The Souveneir $4^{\text {th }}$ national conference of Psychiatrists Assosciation Nepal; 2010 March; Kathmandu, Nepal.

11. Lalwani S, Sharma GA, Kabra SK, Girdhar S, Dogra T. Suicide among children and adolescents in south Delhi (1991-2000). Indian J Pediatr 2004;71(8):7013.

12. Shek DT, Tang V. Adolescent suicide in Hong Kong during 1980-2000. Int J Adolesc Med Health 2003;15(3):245-65.

13. Shaw D, Fernandes JR, Rao C. Suicide in children and adolescents: a 10-year retrospective review. Am J Forensic Med Pathol 2005;26(4):309-15.

14. Uzun I, Karayel FA, Akyildiz EU, Turan AA, Toprak S, Arpak BB. Suicide among children and adolescents in a province of Turkey. $J$ Forensic Sci 2009;54(5):1097-100.

15. Deo BK, Shyangawa PM, Rai DK. Study of suicide pattern in eastern region of Nepal. The Souveneir, $4^{\text {th }}$ national conference of Psychiatrists association Nepal; 2010 March; Kathmandu, Nepal.

16. Dervic K, Friedrich E, Oquendo MA, Voracek $M$, Friedrich $M H$, Sonneck $G$. Suicide in Austrian children and young adolescents aged 14 and younger. Eur Child Adolesc Psychiatr 2006;15(7):427-34.

17. Singh VD, Lathrop SL. Youth suicide in New Mexico: a 26-year retrospective review. J Forensic Sci 2008;53(3):703-8.

18. Ajdacic-Gross V, Wang J, Bopp M, Eich D, Rössler W, Gutzwiller F. Are seasonalities in suicide dependent on suicide methods? A reappraisal. Soc Sci Med. 2003;57(7):1173-81. 
19. Benson J, Shakya R. Suicide prevention in Nepal: a comparison to Australia- a personal view. Ment Health Fam Med 2008;5(3):177-82.

20. Beautrais AL, Joyce PR, Mulder RT. Risk factors for serious suicide attempts among youths aged 13 through 24 years. J Am Acad Child Adolesc Psychiatr 1996;35(9):1174-82.

21. Lewinsohn PM, Rohde P, Seeley JR. Psychosocial characteristics of adolescents with a history of suicide attempt. J Am Acad Child Adolesc Psychiatr 1993;32(1):60-8.

22. Nelson RE, Crawford B. Suicide among elementary school-aged children. Elemen School Guidance Counsel 1990;25:123-8.

23. Ang RP, Huan VS. Relationship between Academic Stress and Suicidal Ideation: Testing for Depression as a Mediator Using Multiple Regression. Child Psychiatr Hum Dev 2006;37(2):133-43.

24. Gould MS, Fisher P, Parides M, Flory M, Shaffer D. Psychosocial risk factors of child and adolescent completed suicide. Arch Gen Psychiatr 1996;53(12):155-62.

25. Pelkonen M, Marttunen M, Pulkkinen E, Laippala $\mathrm{P}$, Aro H. Characteristics of out-patient adolescents with suicidal tendencies. Acta Psychiatr Scand 1997;95: 100-7.

26. Beautrais AL, Joyce PR, Mulder RT. Precipitating factors and life events in serious suicide attempts among youths aged 13 through 24 years. J Am Acad Child Adolesc Psychiatr 1997;36(11):154351.

27. Schmidtke A, Hafner $H$. The Werther effect after televised films: new evidence for an old hypothesis. Psychol Med 1988;18(3):665-76.

28. Simkin S, Hawton K, Whitehead L, Fagg J, Eagle M. A study of the effects of a television drama portrayal of paracetamol self-poisoning. $\mathrm{Br} J$ Psychiatr 1995;167(6):754-9.

29. Grøholt B, Ekeberg $\varnothing$. Suicide in young people under 15 years: problems of classification. Nord $J$ Psychiatr 2003;57(6):411-7. 